\title{
A PROPOSTA TEÓRICO-METODOLÓGICA DE ENSINO DO CONCEITO DE VERBO NOS LIVROS DIDÁTICOS
}

\author{
Débora Francischini Boian ${ }^{1}$, Maria Angélica Olivo Francisco Lucas $^{2}$ \\ ${ }^{1}$ Universidade Estadual do Paraná - UNESPAR, Departamento de Pedagogia, Campo Mourão, PR. ${ }^{2}$ Universidade \\ Estadual de Maringá - UEM, Departamento de Teoria e Prática da Educação Maringá, PR. E-mail: \\ mangelicaofl@ibest.com.br, deborafboian18@gmail.com
}

\section{RESUMO}

Muitos educandos aprendem a definir o verbo apenas como: "ação, estado ou fenômeno da natureza", entendemos que isso impossibilita de operar com o conceito da palavra de modo consciente e arbitrário. Diante dessa problemática, o objetivo deste estudo é analisar as orientações teórico-metodológicas sobre o processo do ensino e aprendizagem do conceito de verbo difundido em livros didáticos destinados aos $3^{\circ}, 4^{\circ}$ e $5^{\circ}$ anos do ensino fundamental. A metodologia constou de análise documental a qual buscou verificar as atividades propostos nestes livros. Os resultados indicam que o ensino da gramática, em especial do conceito de verbo, limitase a exercícios descontextualizados que utilizam frases e palavras soltas, ao invés do uso de gêneros textuais. Entendemos, assim, que tal proposta de ensino presente nos materiais analisados limita o aprendizado da língua e o desenvolvimento do pensamento.

Palavras-chave: Conceito de verbo. Ensino de Gramática. Livro didático. Processo de ensino e aprendizagem. Ensino fundamental.

\section{THE THEORETICAL-METHODOLOGICAL PROPOSAL OF TEACHING THE CONCEPT OF VERB IN TEXTBOOKS}

\begin{abstract}
Many students learn to define the verb only as: "action, state or phenomenon of nature", we understand that this makes it impossible to operate with the concept of the word consciously and arbitrarily. In view of this problem, the objective of this study is to analyse the theoretical and methodological orientations about the teaching and learning process of the verb concept disseminated in textbooks for the 3rd, 4th and 5th years of elementary school. The methodology consisted of documentary analysis which sought to verify the activities proposed in these books. The results indicate that the teaching of grammar, especially the concept of verb, is limited to decontextualized exercises that use sentences and loose words, instead of using textual genres. We understand, therefore, that this teaching proposal present in the analysed materials limits the learning of the language and the development of the thought.
\end{abstract}

Keywords: Verb concept. Grammar teaching. Textbook.Teaching and learning process. ElementarySchool. 


\section{INTRODUÇÃO}

No processo de apropriação da cultura, a escola assume a função de instituição principal na tarefa de ensinar de forma sistematizada os conhecimentos elaborados ao longo da história da humanidade. Esse processo "[...] não ocorre de forma direta, pois depende, fundamentalmente, de uma organização, cujo papel cabe ao professor" (LUCAS, 2008, p. 17). Nesta direção, o objetivo da escola deve ser formar os indivíduos, humanamente, por meio do ensino sistematizado e intencional de conteúdos clássicos.

Segundo Saviani (2011), não se pode confundir a palavra clássico com a palavra tradicional. Em síntese, trabalhar com o clássico significa que a escola deve organizar o trabalho pedagógico com base em conteúdos essenciais, isto é, fundamentais para a apropriação da cultura e, consequentemente, para o desenvolvimento psíquico. Pois os conteúdos clássicos carregam em si uma lógica, linguagem científica, trabalho coletivo humano, abstração e generalização científica.

Partindo desses princípios, definimos como objeto de estudo o ensino da gramática nos anos iniciais da escolarização, em especial o trabalho com o conceito de verbo proposto pelos livros didáticos. De acordo com a Teoria Histórico Cultural (THC), a gramática é um conhecimento clássico; por isso, seu estudo é indispensável à formação dos indivíduos. É com o estudo de conteúdos gramaticais que os sujeitos se conscientizam de forma arbitrária da própria língua materna e de outras línguas. Com base nisso, Vigotski ${ }^{1}$ (2009, p. 319) afirma que "[...] a análise do aprendizado da gramática, como a análise da escrita, mostra a imensa importância da gramática em termos de desenvolvimento geral do pensamento infantil".

Salientamos que não pretendemos, neste artigo, estudar o aprendizado da gramática, como propriamente dito pelo autor mencionado acima, mas objetivamos analisaras orientações teórico-metodológicas sobre o processo do ensino e aprendizagem do conceito de verbo difundido em livros didáticos destinados aos $3^{\circ}, 4^{\circ}$ e $5^{\circ}$ anos do ensino fundamental. Acreditamos que, por eles serem utilizados como instrumento de apoio no encaminhamento de práticas pedagógicas, a organização dos conteúdos apresentada nestes livros influencia o processo de ensino e aprendizagem implementado nas escolas públicas brasileiras, podendo ou não resultar na apropriação dos conteúdos ensinados.

\section{METODOLOGIA}

Trata-se de um estudo de caráter documental, pois se refere à seleção e à análise de livros didáticos. Para analisarmos a proposta de organização do ensino com o conceito de verbo, selecionamos os materiais direcionados para os 3 , 4 e 5 을 anos iniciais do ensino fundamental, na área de língua portuguesa.

Os livros didáticos analisados pertencem ao triênio 2016, 2017 e 2018 e seguem as orientações do Guia do Plano Nacional do Livro Didático (PNLD) e 2016. O livro didático selecionado utilizado no $3^{\circ}$ ano do ensino fundamental intitula-se Português: linguagens, publicado pela Editora Saraiva. Os livros utilizados nos $4^{\circ}$ e $5^{\circ}$ anos são da mesma coleção, denominada Ápis, também publicada pela Editora Saraiva.

\section{RESULTADOS}

No que se refere ao livro do 3 o ano do ensino fundamental, o conceito de verbo está presente em apenas cinco páginas. A definição de verbo é apresentada como uma palavra que indica ação e estado. Para explorar essa definição, o livro apresenta o gênero textual cartum, no qual expõe ações da personagem Gaturro, como amar, chorar, agradecer, perdoar, entre outras.

Consideramos que os exercícios dos livros limitam a ação do aluno de fazer somente cópias das palavras. A cópia por si só não possibilita a apropriação do conceito, pois, nestas condições, é

\footnotetext{
${ }^{1} \mathrm{Na}$ bibliografia existente o nome Vygotski é encontrado grafado de várias formas: Vigotski, Vygotsky, Vygotskii, Vigotskji, Vygotski, Vygotsky. Optou-se aqui por empregar a grafia Vigotski, devido à referência utilizada. 
uma ação automatizada e não-consciente. Entendemos que isso pode impossibilitar que o aluno estabeleça relações entre a definição de verbo, com os verbos presentes no cartum.

Outra proposta de ensino presente no livro didático do 3ㅇaㅅ ano refere-se ao trabalho com os verbos por meio do uso do dicionário. O livro apresenta uma breve explicação de que as palavras presentes no dicionário que terminam em ar, er, ir são verbos. Em seguida, expõe um poema e questões sobre ele, solicitando que o educando retorne ao texto para identificar, indicar, sublinhar e circular verbos.

Em relação às definições de verbo ligadas às propostas de exercícios contidos no livro direcionado ao 3o ano, verificamos que a primeira forma de apresentar o verbo é definindo-o como um marcador de tempo. Nesta ótica, por intermédio de palavras, o verbo indica na sentença os estados das coisas no passado, no presente ou no futuro. Os exercícios que exploram o verbo como marcador de tempo são propostos por meio de trechos de textos. Solicitam aos alunos: identificar o tempo em que às palavras em destaque se referem; reescrever excertos de textos mudando o tempo verbal. Esse mesmo tipo de exercício é proposto para trabalhar com as pessoas da sentença indicada pelo verbo.

Em outro momento, o livro do 30 ano propõe o trabalho apenas com o verbo no tempo passado. A definição que se apresenta é a de que as palavras, quando indicam esse tempo verbal, podem expressar um fato habitual ou um fato que aconteceu e terminou. Para explorar essa definição, os exercícios propostos também são trechos retirados de textos, cujas palavras no passado são destacadas em negrito. Em geral, solicita-se que os educandos indiquem a que tipo de fatos pertencem esses verbos, copiem os trechos e destaquem os verbos no passado.

No livro do $4^{\circ}$ ano, consta uma proposta de trabalho com o uso do verbo no imperativo. A definição para o modo imperativo é a de que ele indica conselhos e sugestões de como se deve fazer algo. Explora essa definição por meio de texto instrucional, no qual há orientaçõespara fazer uma bexiga voadora. O exercício proposto é para que os educandos releiam as instruções e copiem no caderno os verbos no modo imperativopor eles identificados. Além disso, também pede que reescrevam as frases indicando tais verbos.

Nossa análise referente à proposta de trabalho com verbo presente no livro do $4^{\circ}$ ano do ensino fundamental é a de que a definição para tal conceito é apresentada de forma sintética e que os exercícios propostos se limitam a cópias e reescritas. Além disso, restringem o trabalho a trechos de textos que são apresentados de forma descontextualizada. Acreditamos que esses exercícios não possibilitam aos educandos operar mentalmente com o conceito de verbo no passado e no modo verbal imperativo.

No livro do $5^{\circ}$ ano, primeiramente, define-se o verbo como uma forma de marcar o tempo, demonstrando que os fatos podem acontecer no passado, no presente ou no futuro. Para desenvolver esse conteúdo, são expostos trechos de jornais nos quais são destacados os tempos verbais. Para cada passagem, são solicitados exercícios como: copie a alternativa correta; indique o tempo verbal das palavras em negrito; copie os tempos verbais; complete as frases.

Além disso, também se apresentam variações do verbo em tempo e pessoa. Em suma, tais exercícios solicitam que se reescrevam as frases indicando as pessoas que concordam com o verbo. Ao concluir essa etapa, o livro em análise apresenta a seguinte definição para o conceito de verbo: indicar o tempo e a pessoa significa conjugar o verbo.

Os modos verbais também são explorados no livro do $5^{\circ}$ ano do ensino fundamental. Para tanto, o livro mostra palavras que indicam os modos do verbo, no indicativo e no subjuntivo, por meio de trechos de reportagens. O livro solicita aos alunos que leiam, copiem as frases e as palavras que indicam os modos do verbo e escrevam ações que, habitualmente, fazem, fizeram e farão nos próximos dias.

Com base no que foi exposto em cada livro didático, verificamos quê: as definições em relação às classes gramaticais do verbo são expostas por meio de frases diretas e simplistas; 
propõe-se um trabalho limitado e rápido sobre tempos, modos e pessoas do verbo por meio de trechos de textos; os exercícios propostos solicitam apenas leitura, identificação e cópia dos verbos e das frases expostas.

Salientamos que os livros didáticos analisados apenas objetivam definir o que é verbo por meio de frases diretas. Acreditamos que essas proposições não possibilitam aos alunos operar com o conceito de verbo, mas os limitam, a saber, apenas as definições do verbo apresentadas. Portanto, esse tipo de organização de ensino presente nos livros didáticos em análise permite que os educandos saibam apenas dizer que "O verbo indica estado, ação ou fenômeno da natureza", de forma automática e mecânica.

Para contextualizar os verbos, tais livros os apresentam por meio de trechos de textos. Diante disso, percebemos algumas contradições, pois esse material didático deve seguir as orientações dos Parâmetros Curriculares Nacionais (PCNs) e outros documentos nacionais, os quais postulam que o ensino da língua deve ocorrer por meio de gêneros textuais.

\section{DISCUSSÃO}

O conceito de verbo é complexo e, por isso, sua apropriação requer a organização do ensino e a sistematização dos conteúdos, conforme a exigência de cada ciclo escolar. Em outras palavras, "[...] trata-se de organizar o ensino dentro de um determinado espaço (escola), com determinados conteúdos (currículo), abordados de forma sequencial e dosada dentro de um dado tempo (ano letivo, ciclo I, ciclo II etc.)" (MARTINS; MARSIGLIA, 2015, p. 31).

A organização do ensino deve ter como base os conceitos científicos. Em linhas gerais, conceitos científicos correspondem a um nível mais elevado do pensamento, com formas de categorização e generalização mais avançadas. Portanto, o ensino deve ser intencional e oferecer aos educandos o que eles necessitam para se apropriarem dos conceitos científicos, determinando o que e o como ensinar nas várias etapas de desenvolvimento dos educandos. É por isso que, de acordo com a THC, o processo de ensino e aprendizagem exige significação e sentido (GALUCH, SFORNI, 2009).

O processo de ensino deve impulsionar os educandos a tomarem consciência do sentido e do significado dos conteúdos estudados. Sendo assim, o ensino precisa instigar o interesse dos alunos por meio da significação objetiva do conteúdo, motivando-os para a realização das tarefas propostas. Em suma, para que o aluno se aproprie do conhecimento científico, isto é, "[...] para que possa aprender o que a escola tem por objetivo ensinar, é também necessário que se considere o sentido" (PIOTO; ASBAHR, FURLANETTO, 2017, p. 117) do conteúdo ensinado.

Em linhas gerais, o conceito de verbo, como uma classe gramatical da língua portuguesa, é considerado variável e dinâmico, pois realiza flexões em número, grau, gênero, tempo, voz e pessoa. "Do ponto de vista morfológico, são identificadas como verbos as classes que dispõem de um radical e de morfemas flexionais sufixais específicos" (CASTILHO, 2012, p. 392). Do ponto de vista semântico, o verbo exerce a função de expressar a ação, o acontecimento e o estado das coisas.

O verbo é o núcleo de um discurso. Ele realiza a função de situar as coisas em determinado tempo e modo, exprimir o estado, o fato e a ação e indicar qual/quais pessoa/as fazem parte do processo ocorrido demonstrado pelo discurso. Segundo Castilho (2012, p. 415), o verbo pode ser definido como o núcleo do predicado, nas palavras do autor, "Ao predicar, o verbo transfere seus traços semânticos inerentes aos seus argumentos. A predicação retrata o estado das coisas "[...] 0 estado das coisas é uma entidade conceitual". Em síntese, Castilho (2012) pontua que só é possível situar os aspectos gerais que envolvem o verbo, se considerarmos as flexões que ele realiza.

Ernani e Nicola (2001) denominam o verbo como uma palavra de excelência; a sua aprendizagem permite que os sujeitos conheçam a palavra das palavras. Os referidos autores 
defendem essa definição que exalta a importância do conceito em discussão, mostrando que, "[...] na religião, verbo significa a sabedoria eterna e, nos estudos atuais, a expressão linguagem verbal designa a própria língua, ou seja, a forma de comunicação baseada nas palavras" (ERNANI; NICOLA 2001, n.p, grifo dos autores).

Com base nestes esclarecimentos, reafirmamos que o processo de ensino e aprendizagem da língua portuguesa requer a realização de um trabalho com todas as dimensões que envolvem a língua materna, dentre elas os aspectos de caráter morfológico, sintáxico, fonético, semântico e estilístico, pois é com esse sistema de conhecimentos que se torna possível o desenvolvimento da competência linguística.

\section{CONCLUSÃO}

A análise de tais livros indica que os conteúdos que dizem respeito ao conceito de verbo são reduzidos a definições simples e diretas, isto é, não exploram a sua essência. De acordo com Vigotski (2009, p. 247), “[...] a experiência pedagógica nos ensina que o ensino direto de conceitos sempre se mostra impossível e pedagogicamente estéril. O professor que envereda por esse caminho não consegue senão uma assimilação vazia de palavras, um verbalismo puro [...]". Portanto o conceito não é uma mera definição da linguagem, mas, um meio de ação psíquica, na qual se devem estabelecer relações entre significado e palavra.

Sendo assim, se o trabalho com o conceito de verbo for reduzido a definições e exercícios por meio de frases soltas, não haverá aprendizagem e apropriação do conhecimento. $O$ ensino de qualquer conteúdo da gramática deve ocorrer de forma contextualizada e estar relacionado, sobretudo, com a prática social (BOIAN, 2018).

Verificamos que a organização do ensino proposta pelos livros didáticos analisados apresenta-se com as características do ensino da gramática tradicional, em que os conhecimentos linguísticos limitam-se ao estudo com palavras e frases descontextualizadas, impossibilitando, assim, a conscientização dos aspectos gramaticais da língua e, consequentemente, limitando o desenvolvimento da linguagem e do pensamento.

Diante da precarização do trabalho docente, o livro didático se tornou o instrumento mais utilizado como apoio à prática pedagógica; é ele que determina o que será ensinado aos alunos, como e quando, tornando-se a direção do processo de ensino e aprendizagem. Reside aí a relevância da discussão aqui apresentada.

\section{REFERÊNCIAS}

BOIAN, D. F. A gramática nos anos iniciais do ensino fundamental: organização do ensino do conceito de verbo presente nos livros didáticos. 130 f. Dissertação (Mestrado em Educação) Universidade Estadual de Maringá, Maringá, 2018. Disponivel em: <http://www.ppe.uem.br/dissertacoes/2018/2018\%20-\%20Debora\%20Boian.pdf> Acessado em agosto de 2018.

CASTILHO, A. T de. Nova Gramática do Português Brasileiro. 1ạ. Ed, 2a reimpressão. São Paulo: Contexto, 2012.

ERNANI, T; NICOLA, J. de. Verbos: guia prático de emprego e conjugação. São Paulo: Editora Scipione, 2001.

GALUCH, M. T. B; SFORNI, M. S. F. Aprendizagem conceitual e apropriação da linguagem escrita: contribuições da teoria histórico-cultural.Estudos em Avaliação Educacional, v. 20, n. 42, p. 111 124, 2009. Disponível em 
<http://www.fcc.org.br/pesquisa/publicacoes/eae/arquivos/1470/1470.pdf>Acessado em julho de 2018.

LUCAS, M. A. O. F. Os processos de alfabetização e letramento na educação infantil: contribuições teóricas e concepções de professores. 2008. 322 f. Tese (Doutorado em Educação)-Faculdade de Educação, Universidade de São Paulo, São Paulo, 2008. Disponível em: <file:///C:/Users/usuario/Downloads/MariaAngelicaFrancisco\%20(1).pdf>. Acessado em junho 2018.

MARTINS, L.M. MARSIGLIA, A.C.G. As perspectivas construtivista e histórico-crítica sobre o desenvolvimento da escrita. Campinas, SP: Autores Associados, 2015.

SAVIANI, Dermeval. Pedagogia histórico-crítica: primeiras aproximações.11. ed. Campinas, SP: Autores Associados, 2011.

PIOTO, D. C; ASBAHR, F. da S. F; FURLANETTO, F. R. Significação e sentido na psicologia históricocultural: implicações para a educação escolar. In: MOURA, M. O. de (Org). Educação escolar $e$ pesquisa na teoria histórico-cultural. São Paulo: Edições Loyola, 2017.

VIGOTSKI, L. S. A construção do pensamento e da linguagem. São Paulo: Editora WMF Martins Fontes, 2009. 